University of Nebraska - Lincoln

DigitalCommons@University of Nebraska - Lincoln

2010

\title{
Environmentally sensitive life-cycle traits have low elasticity: implications for theory and practice
}

\author{
Valery E. Forbes \\ University of Nebraska-Lincoln, veforbes@umn.edu \\ Mette Olsen \\ Roskilde University, Denmark \\ Annemette Palmqvist \\ Roskilde University, Denmark \\ Peter Calow \\ Roskilde University, Denmark, pcalow2@unl.edu
}

Follow this and additional works at: https://digitalcommons.unl.edu/biosciforbes

Part of the Pharmacology, Toxicology and Environmental Health Commons

Forbes, Valery E.; Olsen, Mette; Palmqvist, Annemette; and Calow, Peter, "Environmentally sensitive lifecycle traits have low elasticity: implications for theory and practice" (2010). Valery Forbes Publications. 1. https://digitalcommons.unl.edu/biosciforbes/1

This Article is brought to you for free and open access by the Papers in the Biological Sciences at DigitalCommons@University of Nebraska - Lincoln. It has been accepted for inclusion in Valery Forbes Publications by an authorized administrator of DigitalCommons@University of Nebraska - Lincoln. 


\title{
Environmentally sensitive life-cycle traits have low elasticity: implications for theory and practice
}

\author{
Valery E. Forbes, ${ }^{1}$ Mette Olsen, Annemette Palmovist, and Peter Calow \\ Department of Environmental, Social and Spatial Change, Roskilde University, Universitetsvej 1, \\ P.O. Box 260, 4000 Roskilde, Denmark
}

\begin{abstract}
The relationships between population growth rate and the life-cycle traits contributing to it are nonlinear and variable. This has made it difficult for ecologists to consistently predict changes in population dynamics from observations on changes in life-cycle traits. We show that traits having a high sensitivity to chemical toxicants tend to have a low elasticity, meaning that changes in them have a relatively low impact on population growth rate, compared to other life-cycle traits. This makes evolutionary sense in that there should be selection against variability in population growth rate. In particular, we found that fecundity was generally more sensitive to chemical stress than was juvenile or adult survival or time to first reproduction, whereas fecundity typically had a lower elasticity than the other life-cycle traits. Similar relationships have been recorded in field populations for a wide range of taxa, but the conclusions were necessarily more tentative because stochastic effects and confounding variables could not be excluded. Better knowledge of these relationships can be used to optimize population management and protection strategies and to increase understanding of the drivers of population dynamics.
\end{abstract}

Key words: chemical stress; Daphnia magna; elasticity; lowest observed effective concentration; matrix population model; population dynamics; sensitivity.

\section{INTRODUCTION}

Environmental variability affects individuals, in terms of causing changes in survival, reproduction, and/or growth, but effects on these life-cycle traits are neither linearly nor consistently related to impacts on population dynamics (Calow et al. 1997, Pfister 1998, Heppell et al. 2000, Forbes et al. 2001). The linkages can be captured by integrating age, size, and stage-specific schedules of reproduction and mortality in population models (Calow and Sibly 1990, Caswell 2001). From these population dynamics models it has become clear that equal impacts on different life-cycle traits do not have equal consequences for population dynamics within species and that equal impacts on the same traits among species have different population-level effects, dependent on life cycle. The demographic importance of life-cycle traits can be defined as either the absolute (called sensitivity) or relative (called elasticity) change in population growth rate (or other population-level measure) resulting from an absolute or relative change in the life-cycle trait (de Kroon et al. 2000). For example, if juvenile survival is a highly elastic trait, this means that small proportional declines in juvenile survival will have a proportionally large negative effect on population growth rate. Conversely large changes in

Manuscript received 14 June 2009; revised 28 September 2009; accepted 7 October 2009. Corresponding Editor: S. K. Collinge.

${ }^{1}$ E-mail: vforbes@ruc.dk traits with a low elasticity will have a relatively small effect on population growth rate.

Effective population management (e.g., for conservation, pest control, environmental risk assessment, and the like) relies on identification of those life-cycle stages or traits that are the primary drivers of population dynamics. There are opposing views as to whether it is the high elasticity traits or the low elasticity traits that drive the dynamics of field populations (Crouse et al. 1987, Ehrlén and van Groenendael 1998, Caswell 2000, de Kroon et al. 2000, Sæther and Bakke 2000, Wisdom et al. 2000). One view is that environmentally caused changes in the highly elastic traits control population dynamics, because even small changes in these are likely to have measurable impacts on population growth. Hence, population management efforts should aim at controlling environmental impacts on the most demographically important age classes or traits (Crouse et al. 1987). However, variability in population growth rate is thought to have negative consequences for fitness, and it has been proposed that natural selection may alter life cycles to minimize stages with both high demographic sensitivity and high variation (Pfister 1998). Thus, an alternative view is that, because the least demographically important traits will be most sensitive to environmental stressors, it is changes in these that will drive population dynamics (Sæther and Bakke 2000). Hence population management efforts should aim at controlling impacts on the most environmentally sensitive age classes or traits. This is now the common practice in 


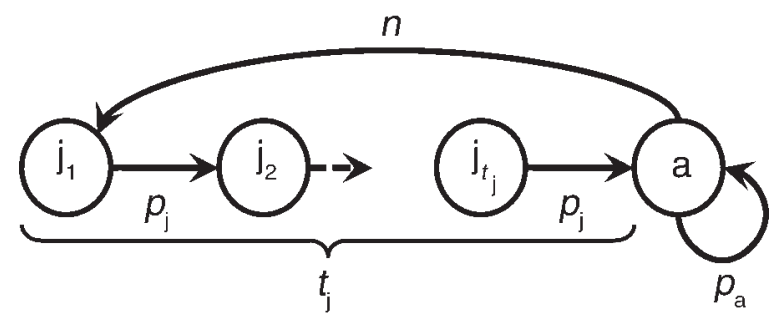

FIG. 1. Life-cycle diagram for a two-stage life cycle. The life cycle consists of an adult stage (a) and a juvenile stage (j) divided into $t_{\mathrm{j}}$ age classes. The number of age classes in the juvenile stage, $t_{\mathrm{j}}$, is not a direct matrix element but is implicit in the matrix in that it determines the matrix dimension. Survival of the adult stage between reproductive events is denoted by $p_{\mathrm{a}}$. Juvenile survival from one age class to the next is denoted by $p_{\mathrm{j}}$, and fecundity, $n$, is the number of offspring per female per reproductive event.

environmental risk assessment, in which ecotoxicity testing strategies assess risk on the basis of the most toxicant-sensitive life-cycle stage or traits (van Leeuwen and Vermeire 2007). The extent to which population management will be more effective by targeting life-cycle stages or traits having high elasticity and/or high environmental sensitivity may depend critically on whether there is a consistent relationship between the demographic and environmental sensitivities of traits. Although convincing evolutionary arguments can be made for a negative relationship between elasticity and environmental variability of life-cycle traits, there are relatively few empirical investigations to confirm theoretical predictions (Horvitz et al. 1997, Ehrlén and van Groenendael 1998, Gallaird et al. 1998, Pfister 1998).

Horvitz et al. (1997) found a negative correlation between demographic sensitivity and variability of matrix elements in the plant Calathea ovandensis. Ehrlén and Groenendael (1998) found a negative correlation between relative variation in matrix elements and their corresponding elasticities in the perennial herb, Lathyrus vernus. Galliard et al. (1998) found a higher elasticity and lower temporal variability in adult survival than in juvenile survival for large herbivores. Sæther and Bakke (2000) found less temporal variation in traits with high elasticities in 49 species of birds. From an analysis of 30 field populations from 17 published studies, Pfister (1998) found a negative correlation between estimates of temporal variance in demographic terms and their contribution to population growth rate. Elasticities for survivorship and growth always exceeded those of fecundity, implying that the former two terms always contributed more to population growth rate than the latter.

Because the above analyses generally used the spatial or temporal variance in demographic terms as a measure of environmental sensitivity, and because the data were taken from a range of field studies, the types of environmental factors influencing trait variability could not be well characterized and probably varied among studies. Spatiotemporal variability in traits could indicate stochastic influences or could indicate that traits are responding to environmental heterogeneity or both. There are also a number of uncertainties involved in estimating life-cycle traits in field populations, and these can potentially lead to bias in demographic analyses. Here we test the hypothesis that a negative correlation exists between elasticities of life-cycle traits and their sensitivity to environmental perturbations in a more controlled way using data from ecotoxicological studies where chemical toxicants are the specific type of environmental perturbation influencing life-cycle traits and consequently population growth rate. Most of the studies involved individual chemicals; however, some included other environmental factors such as food or population density. Because the studies were conducted under controlled laboratory conditions, sampling variability and measurement error of demographic traits were minimal, unbiased sampling of all individuals in the populations could be achieved, and thus estimates of demographic parameters (e.g., survival) are more precise and reliable than those often available from field studies (Gallaird et al. 1998).

Since inputs of chemicals to the environment at levels in excess of those causing toxicity are most often associated with human activities, consistent relationships between life-cycle trait elasticity and chemical sensitivity may not have evolved. However, because organisms use the same biochemical and physiological defense systems to deal with natural stressors and human-caused stressors, general patterns may arise that are independent of stressor origin.

We used a simple, stage-structured population model (Fig. 1) to estimate population growth rate, $\lambda$, from information on adult and juvenile survival $\left(p_{\mathrm{a}}\right.$ and $\left.p_{\mathrm{j}}\right)$, fecundity $(n)$, time to first reproduction $\left(t_{\mathrm{j}}\right)$, and time between reproductive events $\left(t_{\mathrm{a}}\right)$ for populations exposed to different concentrations of toxic chemicals under carefully controlled laboratory conditions. Demographic sensitivities and elasticities were calculated for control treatments (i.e., populations not exposed to toxicants). So that sensitivities of traits to toxicants would be comparable across toxicant types and species, we estimated sensitivity of life-cycle traits as the percentage change in each trait, relative to the control treatment, measured in that treatment in which the most sensitive trait was determined to be statistically different from the control, the so-called lowest observed effect concentration (LOEC), which is used in estimating risk (van Leeuwen and Vermeire 2007).

\section{Methods}

\section{Literature search}

We used Web of Science to conduct a literature search of life-cycle experiments published between 1900 and 2007. The search was restricted to multicellular animals and studies relevant for ecotoxicological testing. In 
most, but not all studies, test organisms were exposed to individual toxic chemicals. In a few cases, studies either combined exposure to toxic chemicals with other variables expected to influence test results (e.g., food type and quantity) or tested factors suspected to influence toxicity test results (e.g., exposure scenario). The former will be referred to as typical studies and the latter as atypical studies. All publications meeting the following criteria were included in the analysis: (1) The experiment started with young juveniles and permitted treatment-dependent estimates of time to first reproduction $\left(t_{\mathrm{j}}\right)$ to be made; (2) survival and reproduction were reported as a function of time or age; (3) experimental conditions (e.g., chemical concentration, temperature, and the like) were maintained at constant levels through the entire duration of the experiment (but see Pieters et al. 2005, Reynaldi and Liess 2005, Pieters and Liess 2006); (4) a lowest observed effect concentration (LOEC) was reported for at least one life-cycle trait. In a limited number of cases, it was necessary to estimate values of life-cycle traits from graphs. A total of 36 publications fit the selection criteria, of which 19 used Daphnia magna as a test organism, in which 17 different chemicals were tested. The remaining 17 publications included 13 additional species and a total of 15 chemicals.

\section{Demographic model calculations}

We used the two-stage matrix model of Calow and Sibly (1990) with a projection interval of one day. The model is $1=n S_{\mathrm{j}} \lambda^{-t_{\mathrm{j}}}+S_{\mathrm{a}} \lambda^{-t_{\mathrm{a}}}$, where $n$ is the mean number of offspring per brood per reproductive individual, $S_{\mathrm{j}}$ is juvenile survival (proportion surviving from birth to first reproduction), $S_{\mathrm{a}}$ is adult survival (the mean probability that a female survives between breeding attempts over the reproductive period), $t_{\mathrm{j}}$ is time for females to reach first reproduction, and $t_{\mathrm{a}}$ is the time between breeding attempts. Since $S_{\mathrm{j}}$ and $t_{\mathrm{j}}$ are not independent, we define the variable $p_{\mathrm{j}}$ such that $S_{\mathrm{j}}=p_{\mathrm{j}}^{t_{j}}$ and use $p_{\mathrm{j}}$ in the elasticity analyses. Since $S_{\mathrm{a}}$ is measured between breeding attempts, it is independent of $t_{\mathrm{a}}$, but for consistency we define $p_{\mathrm{a}}=S_{\mathrm{a}}$. The elasticities (i.e., the proportional effect on $\lambda$ of proportional changes in life-cycle traits) were calculated for the control treatment of each study from the equation $e_{x}=(x / \lambda)(d \lambda / d x)$, where $x$ refers to the life-cycle traits and $d \lambda / d x$ is the sensitivity of $\lambda$ to changes in a particular life-cycle trait. We calculated elasticities of the life-cycle traits according to Levin et al. (1996). The equations for the elasticities of $n$, $t_{\mathrm{j}}, p_{\mathrm{j}}$, and $p_{\mathrm{a}}$ are as follows:

$$
\begin{aligned}
& e_{p_{\mathrm{j}}}=\left(\frac{p_{\mathrm{j}}}{\lambda}\right) \frac{t_{\mathrm{j}} p_{\mathrm{j}}^{\left(t_{\mathrm{j}}-1\right)} n}{\left(t_{\mathrm{j}}+1\right) \lambda^{t_{\mathrm{j}}}-p_{\mathrm{a}} t_{\mathrm{j}} \lambda^{\left(t_{\mathrm{j}}-1\right)}} \\
& e_{t_{\mathrm{j}}}=\left(\frac{t_{\mathrm{j}}}{\lambda}\right)\left|\frac{-\lambda^{\left(t_{\mathrm{j}}+1\right)} \ln \lambda+p_{\mathrm{a}} \lambda^{t_{\mathrm{j}}} \ln \lambda+p_{\mathrm{j}}^{t_{\mathrm{j}}} \ln p_{\mathrm{j}} n}{\left(t_{\mathrm{j}}+1\right) \lambda^{t_{\mathrm{j}}}-p_{\mathrm{a}} t_{\mathrm{j}} \lambda^{\left(t_{\mathrm{j}}-1\right)}}\right|
\end{aligned}
$$

$$
\begin{aligned}
e_{n} & =\left(\frac{n}{\lambda}\right) \frac{p_{\mathrm{j}}^{t_{\mathrm{j}}}}{\left(t_{\mathrm{j}}+1\right) \lambda^{t_{\mathrm{j}}}-p_{\mathrm{a}} t_{\mathrm{j}} \lambda^{\left(t_{\mathrm{j}}-1\right)}} \\
e_{p_{\mathrm{a}}} & =\left(\frac{p_{\mathrm{a}}}{\lambda}\right) \frac{\lambda}{\left(t_{\mathrm{j}}+1\right) \lambda-p_{\mathrm{a}} t_{\mathrm{j}}} .
\end{aligned}
$$

Because we estimated elasticities for life-cycle traits $\left(p_{\mathrm{j}}, p_{\mathrm{a}}, t_{\mathrm{j}}, n\right)$, and not matrix entries, they did not sum to one (Caswell 2001). To allow comparison among studies and species the elasticities were normalized as follows:

$$
n e_{x_{i}}=\frac{e_{x_{i}}}{\sum_{x_{i}} e_{x_{i}}} .
$$

\section{Environmental sensitivity}

The relative sensitivity of life-cycle traits and $\lambda$ to experimental treatments was estimated as the percentage change in the trait relative to the control treatment. Different traits may have different concentrationresponse relationships, which means relative sensitivity among them may vary along a concentration gradient. To provide a common point of comparison, we calculated the relative sensitivity among traits at the lowest observed effect concentration (LOEC) for the most sensitive of the traits as defined in the original study. The LOECs were defined by statistical comparison between the control and the exposed treatments. The environmental sensitivity of each life-cycle trait and $\lambda$ was calculated as

$$
\left(\frac{X_{\mathrm{LOEC}}-X_{\mathrm{Ctrl}}}{X_{\mathrm{Ctrl}}}\right) \times 100
$$

where $x$ is the value of a life-cycle trait or $\lambda$, estimated in either the control treatment of the experiment or at the lowest observed effect concentration. Where chemical toxicants were assessed, the control was the treatment without any added chemical. In two studies where only food was manipulated, we defined the control as the treatment having the highest population growth rate.

\section{RESUlTS}

The relationship between elasticity and toxicant sensitivity of life-cycle traits for all studies is negative and is of the form $y=a x^{-b}$, where $b=\sim 1$ (Fig. 2). Because the data were from ecotoxicological studies, there were a large number of results for the cladoceran Daphnia magna (the most commonly used test organism; see Plate 1), so that it might have biased the outcome. However, Fig. 3 indicates that the relationship was robust to exclusion of data for D. magna. Some of the data were atypical in that they included variables other than chemical toxicants (Stephenson et al. 1991, Martinez-Jeronimo et al. 1994, Postma et al. 1994, Cotelle and Ferard 1996, Levin et al. 1996, LinkeGamenick et al. 1999, Ramirez-Perez et al. 2004, Pieters et al. 2005, Reynaldi and Liess 2005, Pieters and Liess 2006). Again, the analyses in Figs. 2 and 3 indicate that the negative relationship between chemical sensitivity 


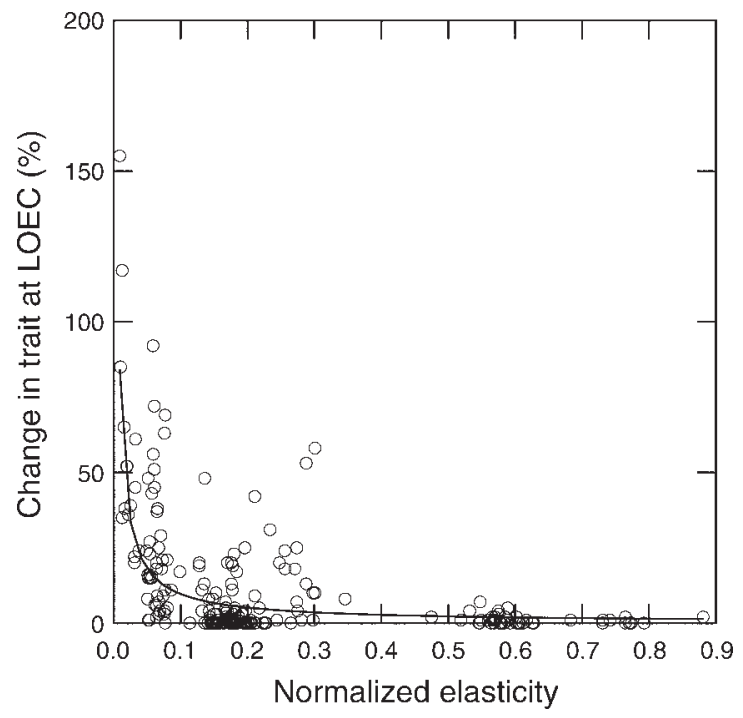

FIG. 2. Sensitivity vs. elasticity for all species. Scatterplot of the elasticities of $n, t_{\mathrm{j}}, p_{\mathrm{j}}$, and $p_{\mathrm{a}}$ against the percentage change in each trait at the lowest observed effective concentration (LOEC) for a total of 54 data sets and 14 species. Both $x$ and $y$ variables are presented as absolute values, and the data are fitted to a power curve. The best-fit linear, least-squares regression to the $\log _{10}$-transformed data is $\log _{10}(Y+1)=$ $-0.055-0.947\left[\log _{10}(X)\right] ; P<0.000000001 ; r^{2}=0.413 ; n=216$ points in the regression. Excluding the atypical tests from the analysis (see Appendix A) had little effect on the shape or significance of the relationship $\left[\log _{10}(Y+1)=-0.040-\right.$ $0.923\left(\log _{10}(\mathrm{X})\right] ; P<0.000000001, r^{2}=0.347, n=156$ points in the regression).

and elasticity of traits was relatively unchanged by omitting atypical studies.

Fecundity was, in general, the most stressor-sensitive trait across all taxa (Tables 1 and 2 and Appendix A). The only exceptions were for the copepod Eurytemora affinis exposed to ketone, where $t_{\mathrm{j}}$ was more sensitive than $n$; the rotifer Brachionus calyflorus exposed to dichloroanaline (DCA), where adult survival was the most sensitive trait, followed by juvenile survival. For all species except $B$. calyflorus, fecundity was the least elastic trait and juvenile survival the most elastic trait. For $B$. calyflorus, $t_{\mathrm{j}}$ was consistently the least elastic trait, whereas highest elasticity fluctuated between adult and juvenile survival. It is unclear why the pattern for $B$. calyflorus differs from the other invertebrates; however, one explanation may be the very short life cycle of the rotifer, for which a model projection interval of one day may be too long. The among-trait differences in elasticity for this species are in any case much smaller than the other species in the data set. For D. magna, fecundity is the least elastic trait and juvenile survival the most elastic trait in all cases (Tables 1 and 2 and Appendix B). In 21 of 29 cases, fecundity was the most toxicant-sensitive trait. The most obvious exception was for tests with fenvalerate, which had a larger impact on time to first reproduction than on fecundity. This may at least partly be explained by the fact that animals were exposed to an initial 24-h pulse of fenvalerate in these studies and then allowed to develop under unexposed conditions. In most of the other studies, exposure continued for the duration of the study. The life-cycle traits for D. magna group into three categories (Fig. 4), with juvenile survival having both a high elasticity and high resistance to chemical impacts. Fecundity has a low elasticity and shows large variation in its sensitivity to chemicals. Adult survival and time to first reproduction have overlapping elasticities and are intermediate in their robustness to chemical impacts, with time to first reproduction showing somewhat more variability.

\section{Discussion}

These analyses support the prediction that natural selection should favor reduced elasticities in life-cycle traits that are sensitive to environmental variations. It also provides further support for the counterintuitive finding that reproductive output seems to generally be the least elastic life-cycle trait. These insights can provide guidance in making population management decisions on the basis of observed effects of environmental variables on individual life-cycle traits: those based on effects on the most sensitive traits are likely to overestimate impacts on population dynamics. There are caveats in terms of the generality of the findings. First our analysis is based on anthropogenic stressors.

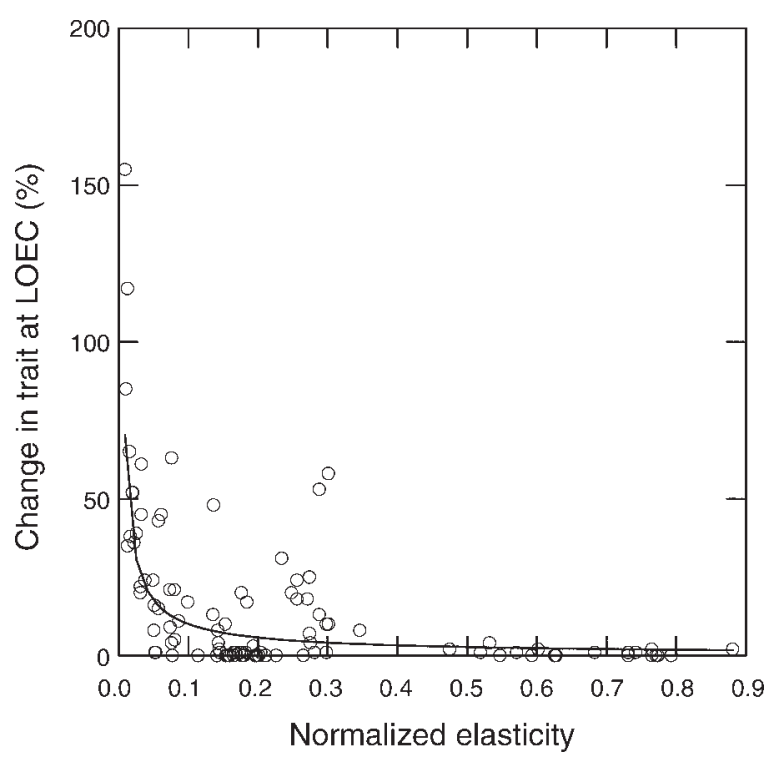

FIG. 3. Sensitivity vs. elasticity without Daphnia magna. Scatterplot of the elasticities of $n, t_{\mathrm{j}}, p_{\mathrm{j}}$, and $p_{\mathrm{a}}$ against the percentage change in each trait at the LOEC as in Fig. 2, but with Daphnia magna omitted. Both $x$ and $y$ variables are given as absolute values, and the data are fitted to a power curve. The best-fit linear, least-squares regression to the $\log _{10}$-transformed data is $\log _{10}(Y+1)=0.044-0.877\left[\log _{10}\right.$ (Elasticity) $] ; P<$ $0.000000001, r^{2}=0.424, n=100$ points in the regression. As with the complete data set, there were no appreciable effects from excluding atypical tests $\left(\log _{10}[Y+1]=0.058-\right.$ $0.836\left[\log _{10}\right.$ (Elasticity)]; $P=0.00000002, r^{2}=0.333, n=80$ points in the regression) (see Appendix B). 
TABLE 1. Rank of elasticities of traits for all studies considered.

\begin{tabular}{ccc}
\hline \hline & $\begin{array}{c}\text { All except } \\
\text { Daphnia magna } \\
\text { (no. cases) } \dagger\end{array}$ & $\begin{array}{c}\text { D. magna } \\
\text { (no. cases) }\end{array}$ \\
\hline$n<t_{\mathrm{j}}<p_{\mathrm{a}}<p_{\mathrm{j}}$ & $12(9)$ & 13 \\
$n<p_{\mathrm{a}}<t_{\mathrm{j}}<p_{\mathrm{j}}$ & $7(5)$ & 13 \\
$t_{\mathrm{j}}<p_{\mathrm{a}}<n=p_{\mathrm{j}}$ & $3(1)$ & 0 \\
$t_{\mathrm{j}}<n=p_{\mathrm{j}}<p_{\mathrm{a}}$ & $2(1)$ & 0
\end{tabular}

Notes: Variables are as follows: $p_{\mathrm{a}}$ is adult survival; $p_{\mathrm{j}}$, juvenile survival; $n$, fecundity; $t_{\mathrm{j}}$, time to first reproductive event. In some studies either more than one species or more than one chemical were tested; we have used each specieschemical test as a case. The cases correspond to the rows of Appendix A and B tables.

$\dagger$ Of a total of 25 cases for species other than D. magna, there was one study in which the same control was used for different treatments, and the elasticity pattern for this study appears only once in the table.

¥ Of a total of 29 cases for D. magna, there were three studies in which the same control was used for different treatments; the elasticity patterns of these three studies only appear once in the table since elasticities were only estimated for the controls.

Though we have already indicated why this should not matter, there is a case for testing the outcomes with other variables. Second, our analysis focuses on invertebrates with relatively short life cycles and is based on laboratory studies in which the values of the life-cycle traits are likely to vary from the field. Previous analyses (Horvitz et al. 1997, Ehrlén and van Groenendael 1998, Gallaird et al. 1998, Pfister 1998, Sæther and Bakke 2000), on the other hand, provide support from a wide range of taxa and life-cycle types from field studies, but the causes of environmental variation in traits could not be precisely characterized. Hence additional cases with a range of taxa and clear sources of environmental variability would give more confidence in the generality of the findings. A detailed understanding of uncertainty and variability of life-cycle traits is important if this type of information is to be applied to field situations.

Forbes and Calow (1999) concluded that there were no consistent patterns in which individual-level traits were most or least sensitive to toxicants. That said, in 50 out of $72(\sim 70 \%)$ of the cases reviewed by Forbes and Calow (1999: Table 2) in which both reproductive traits (i.e., number of broods, brood size, total number of offspring, offspring per day, net reproductive rate, or summed age-specific fecundity) and survival (i.e., life expectancy from birth, mean longevity, maximum longevity, juvenile survival, or adult survival) or development (generation time, time to first reproduction, time between broods) were reported, reproductive traits were more sensitive to toxicants than were survival or development traits. Because the studies used a variety of measures for reproduction and because they were based upon data generated from a range of different kinds of population models, the comparison was not as straightforward as in the present study.
TABLE 2. Rank of sensitivities of traits for all studies considered.

\begin{tabular}{lcc}
\hline \hline \multicolumn{1}{c}{$\begin{array}{c}\text { Sensitivities of } \\
\text { traits to stressors }\end{array}$} & $\begin{array}{c}\text { All except } \\
\text { Daphnia magna } \\
\text { (no. cases) }\end{array}$ & $\begin{array}{c}\text { D. magna } \\
\text { (no. cases) }\end{array}$ \\
\hline$n$ most/least sensitive & $23 / 0$ & $21 / 0$ \\
$p_{\mathrm{j} \text { most/least sensitive }}$ & $0 / 10$ & $0 / 20$ \\
$t_{\mathrm{j}}$ most/least sensitive & $1 / 10$ & $7 / 10$ \\
$p_{\text {a }}$ most/least sensitive & $1 / 10$ & $0 / 20$ \\
\hline
\end{tabular}

Notes: In cases for which more than one trait in a study showed the same percentage change in response to a treatment (typically 0 ) these were treated as having equal sensitivity. Variables are as follows: $p_{\mathrm{a}}$, adult survival; $p_{\mathrm{j}}$, juvenile survival; $n$, fecundity; $t_{\mathrm{j}}$, time to first reproductive event. There was a total of 25 cases for species other than D. magna and a total of 29 cases for D. magna. In some studies either more than one species or more than one chemical were tested; we have used each species-chemical test as a case. The cases correspond to the rows of Appendix A and B tables.

The present analysis has focused on population growth rate, $\lambda$, as the population-level response. However, there are other potentially relevant population-level endpoints, such as population density, carrying capacity, and probability of extinction (Maltby et al. 2001), and more consideration ought to be given to which of these gives the most useful measure of the population-level response for different management contexts. For example, Hayashi et al. (2008) have pointed out the benefits of using equilibrium population size as the endpoint of choice for population-level ecological effects assessments.

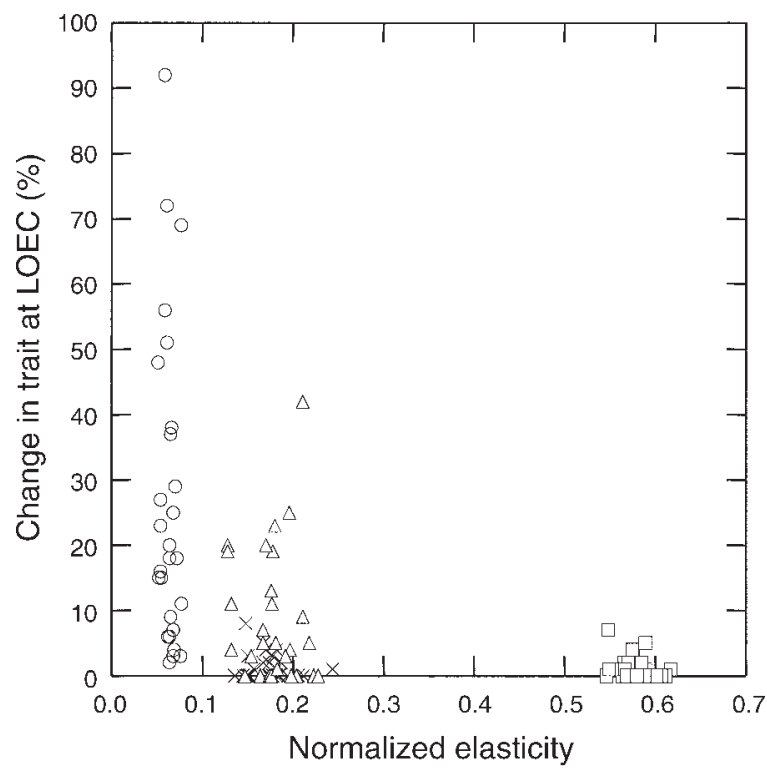

FIG. 4. Sensitivity vs. elasticity for Daphnia magna only. Scatterplot of the elasticities of $n$ (circles), $t_{\mathrm{j}}$ (triangles), $p_{\mathrm{j}}$ (squares), and $p_{\mathrm{a}}$ (crosses) against the percentage change in each trait at the lowest observed effect concentration (LOEC) for Daphnia magna. 


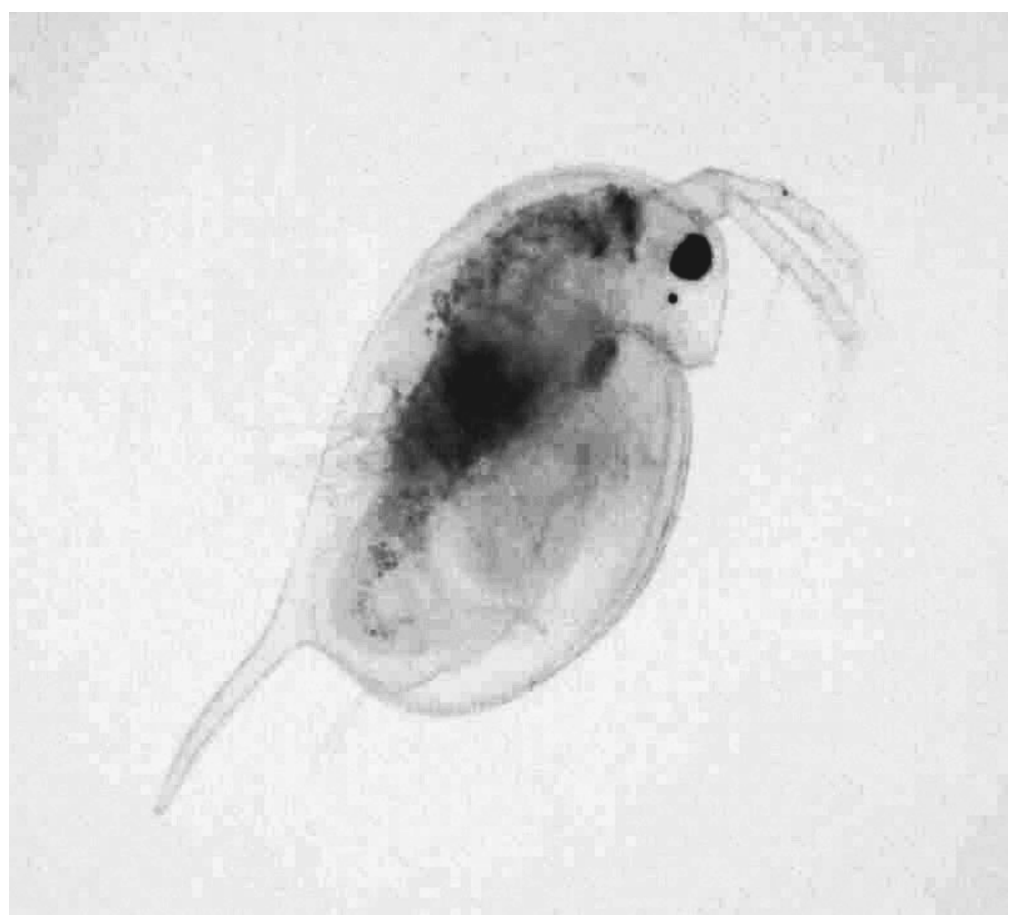

Plate 1. The cladoceran, Daphnia magna, one of the most widely used species in ecotoxicological studies. Photo credit: A. Thit Jensen.

Finally, it has been shown that elasticities of traits vary systematically with population growth rate. Although elasticity estimates are based on the calculation of infinitesimal changes, and the relationship between $\lambda$ and changes in demographic traits is curvilinear, elasticities do seem to provide robust predictions of large changes in $\lambda$ as a result of large changes in demographic parameters (de Kroon et al. 2000). Effective management of populations may depend on knowledge of both elasticity patterns and growth status of the population. If there are consistent negative relationships between elasticity and environmental sensitivity, it should be possible to use these to optimize management strategies that balance the resistance of highly elastic traits to perturbation with the inability of highly variable traits to alter population dynamics. Development of such strategies ought to be subject to detailed scrutiny, ideally by empirical work, on species with representative life cycles and on environmental perturbations likely to be of key management importance.

\section{ACKNOWLEDGMENTS}

This work was partially funded by a grant from the Danish Natural Sciences Research Council (no. 272-05-0161) to V. Forbes.

\section{Literature Cited}

Calow, P., and R. M. Sibly. 1990. A physiological basis of population processes: ecotoxicological implications. Functional Ecology 4:283-288.
Calow, P., R. M. Sibly, and V. E. Forbes. 1997. Risk assessment on the basis of simplified population dynamics scenarios. Environmental Toxicology and Chemistry 16: 1983-1989.

Caswell, H. 2000. Prospective and retrospective perturbation analyses: their roles in conservation biology. Ecology 81:619627.

Caswell, H. 2001. Matrix population models. Second edition. Sinauer Associates, Sunderland, Massachusetts, USA.

Cotelle, S., and J.-F. Ferard. 1996. Effects of algae frozen at different temperatures on chronic assessment endpoints observed with Daphnia magna. Ecotoxicology and Environmental Safety 33:137-142.

Crouse, D. T., L. B. Crowder, and H. Caswell. 1987. A stagebased population model for loggerhead sea turtles and implications for conservation. Ecology 68:1412-1423.

de Kroon, H., J. van Groenendael, and J. Ehrlén. 2000. Elasticities: a review of methods and model limitations. Ecology 81:607-618.

Ehrlén, J., and J. van Groenendael. 1998. Direct perturbation analysis for better conservation. Conservation Biology 12 : 470-474.

Forbes, V. E., and P. Calow. 1999. Is the per capita rate of increase a good measure of population-level effects in ecotoxicology? Environmental Toxicology and Chemistry 18:1544-1556.

Forbes, V. E., P. Calow, and R. M. Sibly. 2001. Are current species extrapolation models a good basis for ecological risk assessment? Environmental Toxicology and Chemistry 20: 442-447.

Gallaird, J.-M., M. Festa-Bianchet, and N. G. Yoccoz. 1998. Population dynamics of large herbivores: variable recruitment with constant adult survival. Trends in Ecology and Evolution 13:58-63.

Hayashi, T. I., M. Kamo, and Y. Tanaka. 2008. Populationlevel ecological effect assessment: estimating the effect of 
toxic chemicals on density-dependent populations. Ecological Research 24:945-954.

Heppell, S., C. Pfister, and H. De Kroon. 2000. Elasticity analysis in population biology: methods and applications. Ecology 81:605-606.

Horvitz, C., D. W. Schemske, and H. Caswell. 1997. The relative "importance" of life-history stages to population growth: prospective and retrospective analyses. Pages 247271 in S. Tuljapurkar and H. Caswell, editors. Structured population models in marine, terrestrial and freshwater systems. Chapman and Hall, London, UK.

Levin, L., H. Caswell, T. Bridges, C. DiBacco, D. Cabrera, and G. Plaia. 1996. Demographic responses of estuarine polychaetes to pollutants: life table response experiments. Ecological Applications 6:1295-1313.

Linke-Gamenick, I., V. E. Forbes, and R. M. Sibly. 1999. Density-dependent effects of a toxicant on life-history traits and population dynamics of a capitellid polychaete. Marine Ecology Progress Series 184:139-148.

Maltby, L., T. J. Kedwards, V. E. Forbes, K. Grasmanm, J. E. Kammengam, W. R. Munnsm, Jr., A. H. Ringwood, J. S. Weis, and S. N. Wood. 2001. Linking individual-level responses and population-level consequences. Pages 27-82 in D. J. Baird and G. A. Burton, Jr., editors. Ecological variability: separating natural from anthropogenic causes of ecosystem impairment. SETAC Press, Pensacola, Florida, USA.

Martinez-Jeronimo, F., R. Villasenor, G. Rios, and F. Espinosa. 1994. Effect of food type and concentration on the survival, longevity, and reproduction of Daphnia magna. Hydrobiologia 287:201-214.

Pfister, C. A. 1998. Patterns of variance in stage-structured populations: evolutionary predictions and ecological implications. Proceedings of the National Academy of Sciences USA 95:213-219.
Pieters, B. J., and M. Liess. 2006. Maternal nutritional state determines the sensitivity of Daphnia magna offspring to short-term fenvalerate exposure. Aquatic Toxicology 76:268277.

Pieters, B. J., A. Paschcke, S. Reynaldi, M. H. S. Kraak, W. Admiraal, and M. Liess. 2005. Influence of food limitation on the effects of fenvalerate pulse exposure on the life history and population growth rate of Daphnia magna. Environmental Toxicology and Chemistry 24:2254-2259.

Postma, J. F., M. C. B. de Jong, N. Staats, and C. Davids. 1994. Chronic toxicity of cadmium to Chironomus riparius (Diptera, Chironomidae) at different food levels. Archives of Environmental Contamination and Toxicology 26:143-148.

Ramirez-Perez, T., S. S. S. Sarma, and S. Nandini. 2004. Effects of mercury on the life table demography of the rotifer Brachionus calyciflorus pallas (Rotifera). Ecotoxicology 13: 535-544.

Reynaldi, S., and M. Liess. 2005. Influence of duration of exposure to the pyrethroid fenvalerate on sublethal responses and recovery of Daphnia magna Straus. Environmental Toxicology and Chemistry 24:1160-1164.

Sæther, B.-E., and Ø. Bakke. 2000. Avian life history variation and contribution of demographic traits to the population growth rate. Ecology 18:642-653.

Stephenson, G. L., N. K. Kaushik, and K. R. Solomon. 1991. Chronic toxicity of a pure and technical grade pentachlorophenol to Daphnia magna. Archives of Environmental Contamination and Toxicology 21:388-394.

van Leeuwen, C. J., and T. G. Vermeire. 2007. Risk assessment of chemicals: an introduction. Second edition. Springer, Dordrecht, The Netherlands.

Wisdom, M. J., L. S. Mills, and D. F. Doak. 2000. Life stage simulation analysis: estimating vital-rate effects on population growth for conservation. Ecology 81:628-641.

\section{APPENDIX A}

A table showing that fecundity is generally the most sensitive and least elastic life-cycle trait across invertebrates (Ecological Archives A020-052-A1).

\section{APPENDIX B}

A table showing that fecundity is generally the most sensitive and least elastic life-cycle trait in Daphnia magna (Ecological Archives A020-052-A2). 